\title{
Gradhiva
}

GRADHIV

Revue d'anthropologie et d'histoire des arts

$14 \mid 2011$

Carl Einstein et les primitivismes

\section{La colonne Durruti, 1936}

\section{Carl Einstein}

Traducteur : Isabelle Kalinowski

\section{OpenEdition}

Journals

Édition électronique

URL : http://journals.openedition.org/gradhiva/2209

DOI : $10.4000 /$ gradhiva.2209

ISSN : 1760-849X

Éditeur

Musée du quai Branly Jacques Chirac

Édition imprimée

Date de publication : 30 novembre 2011

Pagination : 252-256

ISBN : 978-2-35744-046-3

ISSN : 0764-8928

\section{Référence électronique}

Carl Einstein, « La colonne Durruti, 1936 », Gradhiva [En ligne], 14 | 2011, mis en ligne le 30 mai 2012, consulté le 01 mai 2019. URL : http://journals.openedition.org/gradhiva/2209 ; DOI : 10.4000/ gradhiva.2209

(c) musée du quai Branly 


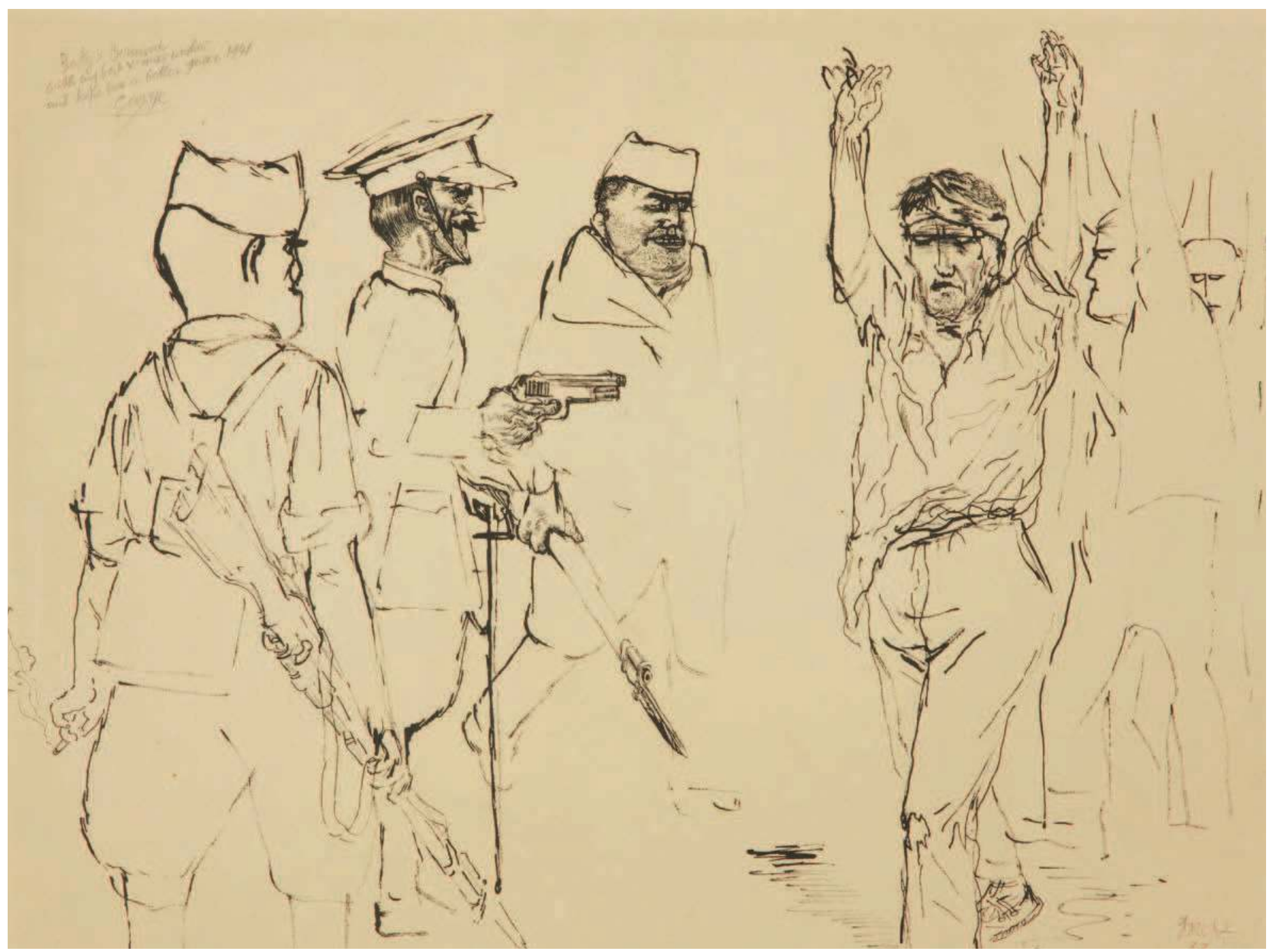

Fig. 1 George Grosz, Espagne, 1937, Museo nacional Centro de Arte Reina Sofia, Madrid ๑ ADAGP, Paris 2011. 


\section{La colonne Durruti}

Ce texte est la retranscription d'une allocution radiophonique prononcée par Carl Einstein en 1936, à Barcelone, à l'occasion de la mort de Buenaventura Durruti. Il parut ensuite dans le recueil Buenaventura Durruti, édité par Helmut Rüdiger en allemand pour le service d'information allemand de la CNT-FAI (Fédération anarchiste), toujours à Barcelone, en 1936. Il est reproduit dans le troisième volume des œuvres complètes de Carl Einstein (édité par Marion Schmid et Liliane Meffre, Berlin, Medusa, 1985, p. 459-462). Il s'agit là de la première traduction française de cette allocution politique.

Notre colonne a appris la mort de Durruti cette nuit. Peu de mots ont été prononcés. Pour les camarades de Durruti, sacrifier sa vie va de soi. L'un d'eux a dit doucement: "C'était le meilleur d'entre nous. " D'autres ont crié dans la nuit : "Nous le vengerons. " Le slogan du jour à venir était : Venganza, vengeance.

Durruti, cet homme extraordinairement pragmatique, ne parlait jamais de lui, de sa personne. Il avait banni de la grammaire le " moi ", ce mot préhistorique. Dans la colonne Durruti, on ne connait que la syntaxe collective. Les camarades vont apprendre aux littérateurs à renouveler la grammaire dans un sens collectif.

Durruti avait reconnu au plus profond de lui-même la force du travail anonyme. L'anonymat et le communisme ne font qu'un. Le camarade Durruti œuvrait à des années-lumière de la vanité des vedettes de gauche. Il vivait avec les camarades, il luttait en compañero. Voilà pourquoi il rayonnait, voilà pourquoi il était pour nous un modèle et nous enthousiasmait. Nous n'avions pas de général; mais la passion de la lutte, l'humilité profonde devant la grande cause, la révolution, irradiaient de ses yeux pleins de bonté et nous touchaient; nos cœurs étaient unis au sien qui continue de battre pour nous dans les montagnes. Nous ne cesserons jamais d'entendre sa voix. Adelante, adelante. Durruti n'était pas un général, c'était notre camarade. Il n'y a là rien de décoratif ; dans cette colonne prolétaire, on n'exploite pas la révolution, on ne fait pas de publicité. On ne pense qu'à une chose : la victoire et la révolution.

Cette colonne anarchosyndicaliste était née dans la révolution. La révolution était sa mère. La guerre et la révolution sont pour nous un seul et même acte, indissociable. D'autres préfèrent faire des choix ou discuter abstraitement. La colonne Durruti ne connaît que l'action, et c'est dans l'action que nous apprenons. Nous sommes de simples empiristes et nous croyons que l'action apporte des idées plus claires qu'un programme point par point qui, dans la violence de l'action, s'enlise.

La colonne Durruti se compose de travailleurs, de prolétaires des usines et des villages. Les ouvriers d'usine catalans ont suivi Durruti, et des camarades de province sont venus les rejoindre. Les ouvriers agricoles et les petits paysans ont quitté leurs villages martyrisés et humiliés par les fascistes, ils sont arrivés de nuit en traversant l'Ebre. La colonne Durruti s'est développée au fur et à mesure qu'elle a conquis et libéré des terres. Née dans les quartiers ouvriers de Barcelone, aujourd'hui, elle rassemble toutes les couches révolutionnaires de la Catalogne et de l'Aragon, des villes et des campagnes.

Les camarades de la colonne Durruti sont des militants de la CNT-FAI. Beaucoup d'entre eux ont payé leurs convictions de peines de prison. Les jeunes se sont connus dans les juventudes libertarias. 


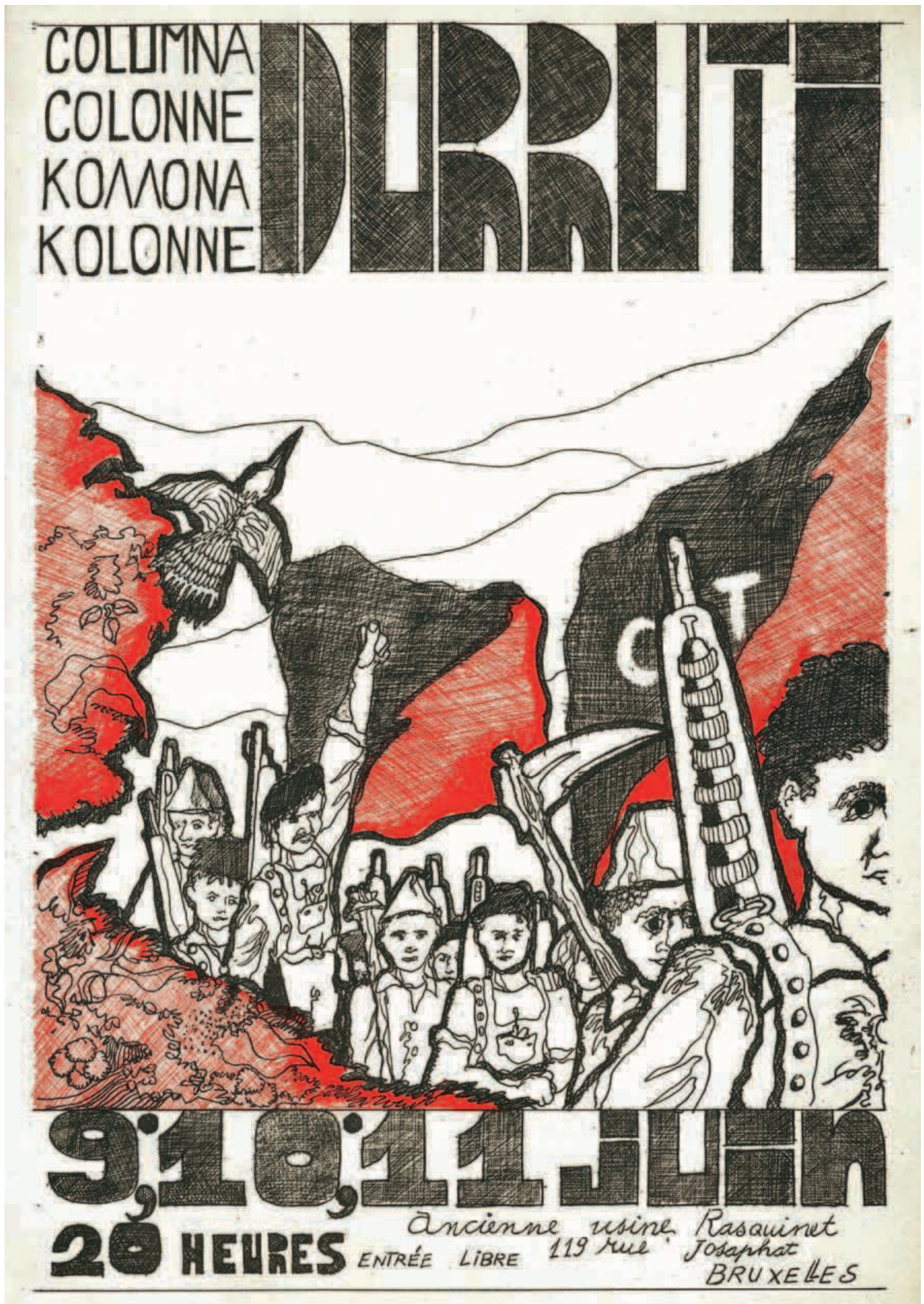

Fig. 2 Affiche pour les représentations de La Colonne Durruti d'Armand Gatti à l'ancienne usine Rasquinet de Bruxelles en 1972 imp. Les Voyelles, Paris @ La Parole errante - Fonds documentaire Armand Gatti. 
Les prolétaires des campagnes et les petits paysans qui nous ont rejoints sont les frères et les fils de ceux qui sont encore opprimés dans les villages. Ils les observent depuis les montagnes. Beaucoup de leurs parents, père et mère, frères et sœurs ont été assassinés par les fascistes. Les paysans regardent, pleins d'espoir et de rancune, la plaine où se trouvent leurs villages. Mais ils ne se battent pas pour leurs hameaux et leurs propriétés, ils se battent pour la liberté de tous. Des garçons, presque des enfants encore, se sont enfuis et nous ont rejoints, des orphelins dont les parents avaient été tués. Ces enfants se battent à nos côtés. Ils parlent peu, mais ils ont compris très tôt beaucoup de choses. Le soir, autour du feu de camp, ils écoutent leurs aînés. Beaucoup ne savent ni lire ni écrire. Les camarades leur apprennent. Quand la colonne Durruti reviendra du front, il n'y aura plus d'analphabètes. C'est une école.

La colonne n'est ni une structure militaire ni une structure bureaucratique. Elle s'est développée de manière organique à partir du mouvement syndical. C'est une fédération sociorévolutionnaire et non une troupe. Nous formons une association de prolétaires opprimés qui lutte pour la liberté de tous. La colonne est l'œuvre du camarade Durruti, qui en a défini l'esprit et qui a défendu son organisation libre jusqu'à son dernier souffle. Le fondement de la colonne est la camaraderie et l'autodiscipline volontaire. L'objectif de son action est le communisme, rien d'autre.

Nous tous haïssons la guerre, mais nous la concevons comme un moyen révolutionnaire. Nous ne sommes pas des pacifistes et nous combattons avec passion ; la guerre - cette idiotie complètement dépassée - ne peut être justifiée que par la Révolution sociale. Nous ne nous battons pas comme des soldats, mais comme des libérateurs. Nous nous imposons, nous avançons non pas pour conquérir des biens mais pour libérer ceux qui sont opprimés par les capitalistes et les pacifistes. La colonne est une association d'idéalistes qui possèdent une conscience de classe. Jusque-là, les victoires et les défaites étaient au service du capital qui entretenait les armées et les officiers afin de garantir et de démultiplier les rentes et le profit. La colonne Durutti est au service du prolétariat. Tout succès de la colonne entraîne la libération des travailleurs dans les lieux où elle a remporté la victoire.

Nous sommes des communistes syndicalistes, mais nous reconnaissons l'importance de l'individu, j'entends par là : tous les camarades ont les mêmes droits et remplissent les mêmes devoirs. Aucun n'est au-dessus des autres, chacun doit développer sa personne au maximum et apporter tout ce qu'il peut. Les techniciens militaires donnent des conseils mais non des ordres. Nous ne sommes peut-être pas des stratèges, mais nous sommes des prolétaires en lutte, il n'y a pas de doute sur ce point. La colonne est forte, c'est un facteur important sur le front, car elle est faite d'hommes qui, depuis longtemps, ne poursuivent qu'un unique objectif, le communisme, et composée de camarades depuis longtemps organisés en syndicats et rompus au travail révolutionnaire. La colonne est une communauté syndicale en lutte.

Les camarades savent que, cette fois, ils combattent pour la classe laborieuse et non pour une minorité capitaliste, pour l'ennemi. Ce constat impose à tous une stricte autodiscipline. Le milicien n'obéit pas mais poursuit avec ses camarades la réalisation de son idéal, une nécessité sociale.

La grandeur de Durruti était justement de ne donner des ordres que rarement, mais d'éduquer en permanence. Les camarades venaient le voir dans sa tente quand il était de retour du front. Il leur expliquait le sens des mesures qu'il avait prises et il discutait avec eux. Durruti ne donnait pas des ordres, il persuadait. Seule la conviction garantit une action claire et résolue. Chez nous, chacun connaît les raisons de son action et les accepte. Voilà pourquoi chacun est prêt à tout pour assurer la réussite de cette action. Le camarade Durruti nous a donné l'exemple.

Le soldat obéit à cause de la peur et de l'infériorité sociale. Il se bat à cause d'un manque. C'est la raison pour laquelle les soldats défendent toujours les intérêts de leurs ennemis sociaux, les capitalistes. Les pauvres diables qui servent du côté des fascistes en livrent le lamentable exemple. Le milicien, lui, se bat avant tout pour le prolétariat, il veut amener la victoire des classes laborieuses. Les soldats fascistes luttent pour une minorité moribonde qui est leur ennemi ; le milicien combat pour l'avenir de sa propre classe. Le milicien semble ainsi plus intelligent que le soldat. La colonne Durruti est disciplinée par un idéal et non par un défilé de parade.

Partout où la colonne s'impose, on collectivise. Les terres sont données à la communauté, les prolétaires des campagnes cessent d'être les serfs des caciques pour devenir des hommes libres. On passe directement du féodalisme terrien au communisme libre. La population est soignée, nourrie et habillée par la colonne. Quand la colonne fait halte dans un village, elle forme une communauté avec la population. Avant, il y avait l'armée et le peuple ou, plus exactement, l'armée contre 


\section{TEXTES DE CARL EINSTEIN}

le peuple. Aujourd'hui, il y a un prolétariat qui travaille et un prolétariat qui lutte, et tous deux forment une unité indissociable. La milice est un agent du prolétariat, sa nature, son organisation sont prolétariennes et doivent le rester. Les milices sont les avant-postes de la lutte des classes. La révolution impose à la colonne une discipline plus stricte que toute forme de militarisation ne pourrait le faire. Chacun se sent responsable du succès de la Révolution sociale. C'est là le contenu de notre lutte, qui restera marquée par cette dominante sociale. Je ne crois pas que des généraux ou le salut militaire puissent nous apprendre une attitude plus appropriée. Je suis sûr, en disant cela, d'être en accord avec Durruti et mes camarades.

Nous ne renions pas notre antimilitarisme d'autrefois, notre saine méfiance à l'égard des visions schématiques des militaires, qui n'ont jusqu'ici profité qu'aux capitalistes. On s'est justement servi d'un tel schématisme pour empêcher les prolétaires de développer leur personnalité et pour les maintenir dans un état d'infériorité sociale. Le schématisme militaire était censé mater la volonté et l'intelligence des prolétaires. Enfin, aujourd'hui, nous combattons contre des généraux mutins. L'existence de la rébellion militaire trahit la valeur douteuse de la discipline militaire. Nous n'obéissons pas à des généraux mais nous poursuivons la réalisation d'un idéal social qui implique, entre autres, le développement maximal de l'individualité prolétaire. La militarisation, en revanche, a été jusqu'ici un moyen volontiers utilisé pour réduire au minimum la personnalité du prolétaire. Nous tous accomplirons, dans la mesure de nos forces, les lois de la révolution. La base de notre colonne est la confiance mutuelle et la collaboration volontaire. Nous laissons volontiers aux fascistes le fétichisme du chef et la fabrication des vedettes. Nous restons des prolétaires armés qui s'imposent librement une discipline en vue d'une fin.

Pour comprendre la colonne Durruti, il faut savoir qu'elle restera toujours la fille et la combattante de la révolution prolétarienne. La colonne incarne l'esprit de Durruti et de la CNT-FAI. Durruti continue de vivre dans notre colonne. Elle conserve fidèlement son héritage. La colonne se bat avec tous les prolétaires pour la victoire de la révolution. C'est ainsi que nous honorons la mémoire de notre camarade Durruti, tombé au front.
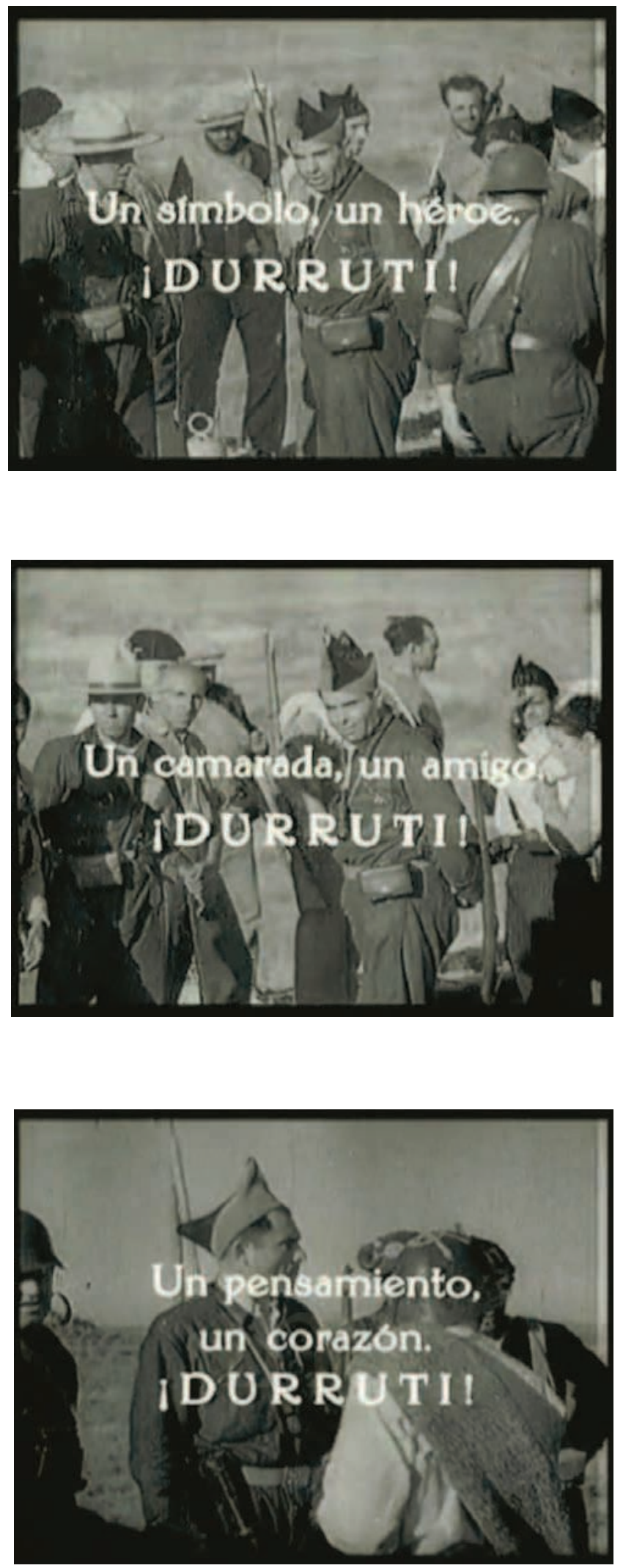

Fig. 3 Photogrammes d'un film sur Buenaventura Durruti, DR. 